\title{
MITRAL VALVOTOMY IN YOUNG PATIENTS
}

\author{
BY
}

\author{
GEORGE CHERIAN, K. I. VYTILINGAM, I. P. SUKUMAR, AND N. GOPINATH \\ From the Departments of Cardiology and Thoracic Surgery, Christian Medical College Hospital, \\ Vellore, South India \\ Received June 6, 1963
}

There have been many reports in the past few years of the results of mitral valvotomy (Sellors, Bedford, and Somerville, 1953; Goodwin et al., 1955; Logan and Turner, 1953, 1959; Ellis, Harken, and Black, 1959; Baker and Hancock, 1960; and others). However, the majority of patients reported on are in the "older" group above 20 years. Reports on young patients who had mitral valvotomy are relatively few. Angelino et al. (1956) reported on 11, Gray (1958) on 3, and Borman et al. (1961) on 13 patients. In these three series the younger group formed only a small percentage of the total number of mitral valvotomies. This report is based on the first 126 patients below the age of 20 years (average 15.5 years) with mitral stenosis who were submitted to mitral valvotomy at the Christian Medical College Hospital from 1954 to 1961. These young patients formed 34 per cent of the total of 373 mitral valvotomies.

\section{INCIDENCE}

Age. Out of the 126 patients, 3 were under 10 years, 33 were between 10 and 15 years, and 90 were between 15 and 20 years. The high incidence in young patients is in contrast with other published figures (Table I). This shows an incidence varying from 1 to 8 per cent in different countries. The relatively high incidence from Israel (Borman et al., 1961) is interesting when one considers the age at onset of rheumatic fever in that country. As our patients are drawn from different parts of India, we believe that our high incidence in young patients is fairly representative of the whole country.

Sex. Of the 126 patients, 71 were male and 55 were female, a preponderance of male over female of 1.3 to 1 . Most reports have a female preponderance around 4 to 1 (Sellors et al., 1953; Goodwin et al., 1955). The reason for the large number of male patients in our group is not clear as this cannot be explained by selective admission.

TABLE I

Comparison of Incidence of Mitral Valvotomy in Young Patients

\begin{tabular}{l|c|c|c|c}
\hline \multicolumn{1}{c|}{ Author } & Country & Age (yr.) & $\begin{array}{c}\text { Total } \\
\text { valvotomies }\end{array}$ & $\begin{array}{c}\text { Younger group } \\
\text { as percentage } \\
\text { of total }\end{array}$ \\
\hline Logan and Turner (1953) & U.K. & $<19$ & 100 & 1 \\
Goodwin et al. (1955) & U.K. & $<20$ & 75 & 3 \\
Bailey and Bolton (1956) & U.S.A. & $<20$ & 1000 & 1 \\
Angelino et al. (1956) & Italy & $<16$ & 600 & 2 \\
Glover (1959) & U.S.A. & $<18$ & 1500 & 1 \\
Borman et al. (1961) & Israel & $<16$ & 173 & 8 \\
Present series (1963) & India & $<20$ & 373 & 34 \\
\hline
\end{tabular}


Economic and Nutritional Status. The economic status has been judged by their admission into the private wards as paying patients or into the general wards as paying or free patients. The last category has been taken as "poor" and formed 35 per cent of the present series. In India this implies dietary deficiencies as well (Rao and Rao 1958). The general nutritional status was designated as "good", "average", or "poor" and was noted to be poor in 43 per cent. This poor nutritional status is no doubt partly related to the early onset of the disease and its effects on growth. This is confirmed by the striking spurt in growth observed after operation in most of the young patients.

Rheumatic Fever. A history suggestive of rheumatic fever was given by 53 per cent of patients: 12 per cent had more than one attack. Chorea was not recorded in any instance. An atrial biopsy was performed in 117 cases: Aschoff bodies were present in 54 per cent. Borman et al. (1961) also had positive biopsies in 54 per cent of their young patients: these figures are higher than the usual reports of 43-44 per cent (Goodwin et al., 1955; Baker and Hancock 1960) for older patients.

\section{SYMPTOMS}

Duration of Symptoms. Wood (1954a, b) mentions a latent interval of 19 years from the initial attack of rheumatic fever before breathlessness appears and an average of $7 \cdot 3$ years for further progression to total incapacity. It is our impression that the rheumatic process progresses more

TABLE II

Total Duration from Rheumatic Attack or INITIAL SYMPTOMS TO OPERATION

\begin{tabular}{c|c}
\hline Duration (yr.) & Percentage of patients \\
\hline$<3$ & 61 \\
$3-5$ & 22 \\
$5-8$ & 14 \\
$8-12$ & 3 \\
$>12$ & Nil \\
\hline
\end{tabular}

TABLE III

DURATION OF DYSPNCEA

\begin{tabular}{c|c}
\hline $\begin{array}{c}\text { Duration of dyspnœa } \\
\text { (mth.) }\end{array}$ & Percentage of patients \\
\hline$<6$ & 10 \\
$6-12$ & 22 \\
$12-36$ & 48 \\
$36-60$ & 18 \\
$>60$ & 3 \\
\hline
\end{tabular}

TABLE IV

Functional Grade before Operation

\begin{tabular}{c|c}
\hline $\begin{array}{c}\text { Grade before operation } \\
1-4\end{array}$ & Percentage of patients \\
\hline 1 & Nil \\
2 & 25 \\
3 & 56 \\
4 & 20 \\
\hline
\end{tabular}
rapidly to critical mitral stenosis in this country: 61 per cent of our patients had a total duration of less than three years from the initial symptoms including rheumatic fever to the time of operation (Table II). The duration of symptoms in young patients has also been short in other reports as well (Angelino et al., 1956; Gray, 1958; Borman et al., 1961).

The duration of effort intolerance (Table III) from the initial symptoms of breathlessness before reaching grades 3-4 and requiring surgical relief was less than 3 years in 79 per cent of our patients.

Dyspnoea. We have graded dyspnœa from grade 1-4 after Wood (1954a, b), grade 1 representing slight incapacity, grade 2 moderate incapacity, grade 3 severe incapacity, and grade 4 total incapacity. 25 per cent of the patients belonged to grade 2 and 75 per cent to grades 3 and 4 (Table IV).

Chest pain. Vague chest pain was present in 21 per cent of patients and angina of effort in 1 per cent. Wood $(1954 a, b)$ gives an incidence of 12 per cent for angina of effort.

Hamoptysis. This was present in 18 per cent (Table V), which is less than the figure of 44-50 per cent quoted by Wood $(1954 \mathrm{a}, \mathrm{b})$. Angelino et al. (1956) report that hæmoptysis is a common feature in children, and it occurred in 4 of their 13 patients.

Embolism. A history of embolism was obtained in only 1 patient (Table V). It did not 
TABLE V

Percentage of Cases with Associated Features

\begin{tabular}{|c|c|c|c|c|}
\hline \multicolumn{4}{|c|}{ Associated features } & Percentage of patients \\
\hline $\begin{array}{l}\text { Congestive cardiac } \\
\text { Hæmoptysis } \\
\text { Aortic valve invol } \\
\text { Atrial fibrillation } \\
\text { Embolism } \\
\text { Angina pectoris }\end{array}$ & $\begin{array}{c}\text { ilure } \\
\ldots \\
\text { aent } \\
\ldots \\
\ldots \\
.\end{array}$ & $\begin{array}{l}\ldots \\
\cdots \\
\cdots \\
\cdots \\
\cdots\end{array}$ & $\begin{array}{l}\ldots \\
\cdots \\
\cdots \\
\cdots \\
\cdots\end{array}$ & $\begin{array}{r}37 \\
18 \\
4 \\
2 \\
1 \\
1\end{array}$ \\
\hline
\end{tabular}

occur in any of the young patients reported by Angelino et al. (1956), Gray (1958), or Borman et al. (1961). Sellors et al. (1953) noted embolism in 9 per cent of their cases, and Goodwin et al. (1955) in 16 per cent of their cases.

Congestive cardiac failure. A history suggestive of congestive cardiac failure was given by 33 per cent of patients and 8 per cent had more than one episode.

Signs. There were no significant differences in the signs of mitral stenosis in the younger when compared to the older patients. The first sound was almost always loud as the incidence of calcification and grossly distorted valves was less in the young patients. Clinical pulmonary hypertension as judged by the parasternal lift and pulmonary component of the second sound was present in all the patients and was judged to be moderate or severe in 79 per cent. In a few of the early patients who had right heart catheterization studies, the average pulmonary arterial systolic pressures recorded were around $81 \mathrm{~mm}$. Hg. The highest pressure recorded was 150 $\mathrm{mm} . \mathrm{Hg}$ in an 18-year-old girl who died after operation.

Signs of congestive cardiac failure such as a raised venous pressure, enlarged liver, and œdema were observed in 37 per cent (Table V). A tender liver was found in 36 per cent of the young patients reported by Angelino et al. (1956). Associated aortic valve involvement was present in $5(4 \%): 4$ of them had both aortic stenosis and regurgitation and 1 had only regurgitation, but these associated lesions were considered significant in only 2 patients (Table V). Atrial fibrillation was present in only 3 patients $(2 \%)$ : this also explains the low incidence of embolism, as 2 out of every 3 patients with a history of embolism have atrial fibrillation (Wood, 1954a, b). The incidence of atrial fibrillation is much lower than the usually reported 40 per cent (Logan and Turner, 1953); (Wood, $1954 a, b)$.

\section{Radiological Features and Electrocardiogram}

The left atrium was enlarged in all the patients and was visible at the right cardiac border in 67 per cent and projected beyond it in a further 6 per cent (Table VI). In no instance was it aneurysmal in size overshadowing all the other chambers. Pulmonary venous (hilar) congestion was present in 85 per cent, horizontal costophrenic lines (Kerley, 1933) in 55 per cent, and hæmo-

TABLE VI

Radiological Features

\begin{tabular}{lll|r}
\hline \multicolumn{2}{c|}{ Radiological features } & \multicolumn{2}{c}{ Percentage of patients } \\
\hline Cardiothoracic ratio over & $50 \%$ & $\ldots$ & 45 \\
Hilar congestion $\ldots$ & $\ldots$ & $\ldots$ & 85 \\
Left atrial enlargement. & $\ldots$ & $\ldots$ & 100 \\
Hæmosiderosis .. $\ldots$ & $\ldots$ & $\ldots$ & 2 \\
Horizontal costophrenic lines & $\ldots$ & 55 \\
\hline
\end{tabular}


TABLE VII

ELECTROCARDIOGRAM

\begin{tabular}{ll|c}
\hline & & Percentage of patients \\
\hline $\begin{array}{l}\text { Right ventricular } \\
\text { hypertrophy }\end{array}$ & \{ominant R in V1 & 65 \\
& S greater than R in V5 & 16 \\
Nil & 19 \\
P wave & Left atrial & 77 \\
& Right atrial & 13 \\
Normal & 10 \\
Atrial fibrillation & - & 2 \\
\hline
\end{tabular}

siderosis in 2 per cent. The pulmonary vascular pattern was assessed as suggested by Davies et al. (1953): the pulmonary hypertension was considered to be mild in 8 per cent and moderate or severe in 87 per cent.

Atrial fibrillation was present in 2 per cent and sinus rhythm in the remaining 98 per cent (Table VII). The QRS axis was between $+90^{\circ}$ and $+180^{\circ}$ in 76 per cent and between 0 and $+90^{\circ}$ in the remaining 24 per cent of patients. A "left atrial $P$ wave" was present in 77 per cent and a "right atrial $P$ wave" in 13 per cent. The remaining 10 per cent had normal $P$ waves. Wood $(1954 a, b)$ recorded a "left atrial $P$ wave" in 98 per cent of his patients, and a "right atrial P wave" in 2 per cent.

A dominant $\mathrm{R}$ in lead $\mathrm{V} 1$ indicating right ventricular hypertrophy was present in 65 per cent of the patients. In 16 per cent there was either a dominant $S$ in V5, a tall $R$ in aVR, or inverted $T$ waves over the right præcordial leads, suggesting right ventricular hypertrophy. In the remaining 19 per cent none of these criteria were present.

\section{OPERATION AND FINDINGS}

Splitting of the valve was done either with the finger alone or with the use of a dilator: lately there has been an increasing use of the dilator to the virtual exclusion of the finger alone.

Left Atrial Thrombus. A left atrial thrombus was present in only 4 per cent (Table VIII) as compared to 20 per cent of the patients reported on by Logan and Turner (1953) and 19 per cent by Goodwin et al. (1955).

Calcification. Calcification of the mitral valve was present in only 6 per cent of patients: of these only 2 per cent had heavy calcification. This again is quite different from the reports in other series, which vary around 40 per cent (Goodwin et al., 1955). Borman et al. (1961) found calcification of the valve in 3 of their 13 patients below 16 years: in 2 of these the history of the illness was

TABLE VIII

Findings at OPERATION

\begin{tabular}{|c|c|c|}
\hline Findings at operation & & Percentage of patients \\
\hline 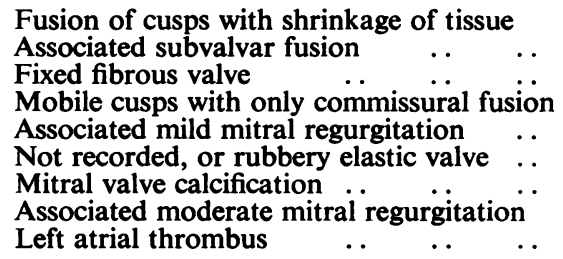 & $\begin{array}{l}\cdots \\
\cdots \\
\cdots \\
\cdots \\
\cdots \\
\cdots \\
\cdots \\
\cdots\end{array}$ & $\begin{array}{r}48 \\
31 \\
29 \\
14 \\
11 \\
9 \\
6 \\
5 \\
4\end{array}$ \\
\hline
\end{tabular}


present for more than three years. The incidence of calcification with its attendant risks appears to increase with age.

Subvalvar Fusion. Subvalvar fusion was present in 31 per cent of patients. The valve itself was found to be mobile with commissural fusion in 14 per cent; fused with shrinkage of cusp tissue in 48 per cent; fibrous (fish-mouth) in 29 per cent; and yielding and rubbery in 1 per cent. In 8 per cent the type of valve was not recorded (Table VIII).

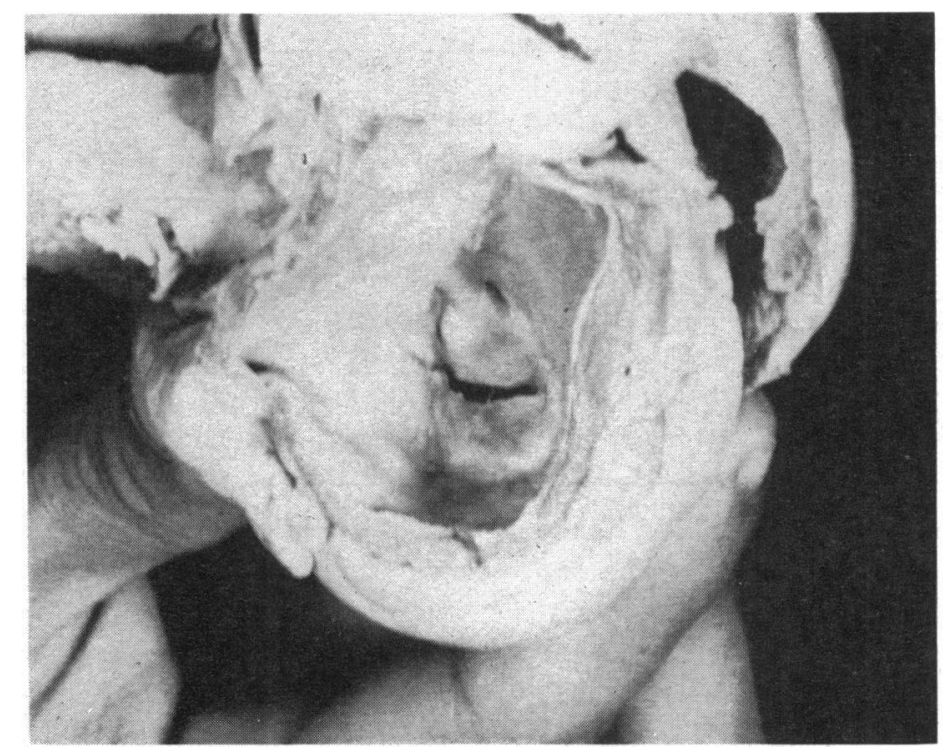

FIG. 1.-Extreme narrowing of the mitral valve in a child of 8 years, who died of congestive heart failure.

Size of the Mitral Valve at Operation. The valve orifice measured less than $1 \mathrm{~cm}$. in diameter in 87 per cent of patients and between $1-1.5 \mathrm{~cm}$. in 11 per cent (Table IX): in 2 per cent the size of the valve was not recorded. In Goodwin et al.'s (1955) series 56 per cent of the valves were less than $1 \mathrm{~cm}$., 37 per cent were between 1 and $1.5 \mathrm{~cm}$. and 5 per cent between 1.5 and $2 \mathrm{~cm}$. In our first group (with valve orifice less than $1 \mathrm{~cm}$.), 41 per cent had a valve measuring less than $0.5 \mathrm{~cm}$.: thus 87 per cent had very tight stenosis. Tight stenosis has also been a feature in other young patients (Angelino et al., 1956; Gray, 1958; Borman et al., 1961). In 23 of our patients who had left atrial punctures, the average left atrial end diastolic pressure was $23 \mathrm{~mm}$. $\mathbf{H g}$, emphasizing the severe degree of stenosis. The Figure shows the mitral valve of an 8-year-old child who died of congestive cardiac failure, and it indicates the extreme narrowing.

Mitral Regurgitation. An insignificant degree of associated mitral regurgitation was present in 11 per cent and a moderate degree in 5 per cent (Table VIII). Goodwin et al. (1955) found mitral regurgitation before valvotomy in 17 per cent of their patients.

\section{Post-OPerative Course}

After operation moderate mitral regurgitation was noticed in 13 per cent and severe regurgitation in 2 per cent of the patients.

Of the 3 patients who had atrial fibrillation before operation, the rhythm spontaneously reverted to normal in 1 , and persisted in the other 2 . In one patient, atrial fibrillation developed 
TABLE IX

Size of Mitral Valve at Operation

\begin{tabular}{c|c}
\hline $\begin{array}{c}\text { Size across the orifice } \\
(\mathrm{cm} .)\end{array}$ & Percentage of patients \\
\hline$<0.5$ & 41 \\
$0.5-1$ & 45 \\
$1-1 \cdot 5$ & 11 \\
Not recorded & 2 \\
\hline
\end{tabular}

TABLE $X$

Operative Mortality in Relation to Pre-Operative Grade of Effort Intolerance

\begin{tabular}{c|c|c}
\hline $\begin{array}{c}\text { Pre-operative grade } \\
1-4\end{array}$ & $\begin{array}{c}\text { Number of } \\
\text { cases }\end{array}$ & $\begin{array}{c}\text { Mortality } \\
\text { percentage }\end{array}$ \\
\hline 1 & Nil & - \\
2 & 31 & Nil \\
3 & 70 & 10 \\
4 & 25 & 40 \\
All grades & 126 & $13 \cdot 5$ \\
\hline
\end{tabular}

for the first time after operation: in this patient it persisted, requiring the use of quinidine which resulted in reversion to sinus rhythm.

Two patients developed joint pains with swelling within a week of the operation. The joint involvement, constitutional upset, and lack of significant chest pain suggested an activation of rheumatic fever rather than the post-commissurotomy syndrome (Papp and Zion, 1956). Both these patients were treated with steroids, made a good recovery, and have remained free of breathlessness and late rheumatic reactivation subsequently. Angelino et al. (1956) noticed a rheumatic flare-up in 1 of their 11 patients in the early post-operative period.

Mortality. The mortality was relatively high $(13 \%)$ but is no higher in the younger than the older patients. Table $\mathrm{X}$ shows the mortality in relation to the grade of dyspnœa before operation. Thus with no deaths in grade 2 , there was a progressive rise in mortality to 10 per cent in grade 3 and 40 per cent in grade 4.

We believe that the high mortality encountered reflects many factors such as poor nutrition, severe pulmonary hypertension, and an advanced stage of the disease: 37 per cent of the patients were admitted in congestive cardiac failure. We have no evidence that persisting rheumatic activity was in any way responsible for the relatively high mortality, as comparable figures were present in our older patients as well. Baker and Hancock (1960) reported a mortality of 11 per cent in 239 patients.

\section{Follow-UP}

We have been able to follow 70 per cent of our patients for periods varying from one to seven years: this has not been easy as they were drawn from different parts of this large country. We have graded the improvement as excellent, good, fair, or poor after Baker and Hancock (1960). Thus excellent means an improvement of 3 grades, good an improvement of 2 grades, fair of 1 grade, and the poor have remained the same.

It can be seen from Table XI that 17 per cent had excellent, 51 per cent good, 28 per cent fair, and 3 per cent poor results: 1 per cent died during the follow-up. Thus 68 per cent had a satisfactory result and 96 per cent of the survivors improved as a result of the operation; while before operation 75 per cent belonged to grades 3 and 4 , after operation 83 per cent were in grades 0 to 1 . 
TABLE XI

RESULTS OF FOLLOW-UP

\begin{tabular}{|c|c|c|}
\hline Result & & Percentage of patients \\
\hline $\begin{array}{l}\text { Excellent: } 3 \text { grades of improvement } \\
\text { Good: } 2 \text { grades of improvement } \\
\text { Fair: } 1 \text { grade of improvement } . . \\
\text { Poor: no improvement .. } \\
\text { Death during follow-up }\end{array}$ & $\begin{array}{l}\cdots \\
\cdots \\
\cdots \\
\cdots\end{array}$ & $\begin{array}{r}17 \\
51 \\
28 \\
3 \\
1\end{array}$ \\
\hline
\end{tabular}

TABLE XII

COMPaRison OF INCIDENCE OF RHeUmatic Reactivation dURING Follow-uP

\begin{tabular}{l|c|c|c}
\hline \multicolumn{1}{c|}{ Author } & Country & $\begin{array}{c}\text { Age-group } \\
\text { (yr.) }\end{array}$ & $\begin{array}{c}\text { Percentage with rheumatic } \\
\text { activation during } \\
\text { follow-up }\end{array}$ \\
\hline Goodwin et al. (1955) & U.K. & Mixed & 3 \\
Baker and Hancock (1960) & U.K. & Mixed & 5 \\
Borman et al. (1961) & Israel & $<16$ \\
Present series (1963) & India & $\{<20$ & Nil \\
& $\{21$ & 15 \\
\hline
\end{tabular}

Rheumatic Reactivation. We have been particularly interested in rheumatic reactivation during the follow-up period as this may be expected to be high in young patients. Rheumatic reactivation has been assessed from the occurrence of significant joint pains with or without fever. Table XII shows that while the incidence of rheumatic reaction during follow-up was high in our patients, it was in fact less in the younger group as compared with our older group. Only a small number of the patients have been on either sulphonamides or penicillin for long-term prophylaxis. We have not as yet carried out a follow-up study of the incidence of reactivation in relation to long-term drug prophylaxis, as most of the patients discontinue therapy in a very short time. There was no correlation between the post-operative rheumatic recurrence and the severity and activity of the rheumatic process as judged from the atrial biopsy.

Restenosis. Over the years only one patient has developed restenosis. He was operated on in 1957, and when seen after four years, he had evidence of restenosis. He refused a second operation. At the first operation he had a valve that measured $0.8 \mathrm{~cm}$. across: a full split of only one commissure was achieved. The atrial biopsy showed no Aschoff bodies, and there was no rheumatic recurrence during the follow-up period.

Restenosis has thus not as yet proved to be a serious problem in young patients.

\section{Discussion}

The high incidence of young patients reported here requiring mitral valvotomy is unusual and not easily explained. Many factors such as the early onset of rheumatic fever, variations in the nature of the disease, host response, and malnutrition may be important. An earlier report from this hospital (Vaishnava, Webb, and Joseph, 1960) has shown that of 166 children under 12 years with rheumatic heart disease, $23(14 \%)$ were 5 years or less at the time of onset of the disease. In a report from Israel (Borman et al., 1961) of 122 patients in hospital for rheumatic heart disease in that country, 20 per cent had their first attack of rheumatic fever when they were under 5 years. These findings are opposed to the rarity of rheumatic fever under 6 years (Keith, Rowe, and Vlad, 1958). 
There are noticeable differences between rheumatic heart disease as seen in India and as reported from western countries. All physicians writing on this subject from India are agreed that chronic valvular disease is very much more common than acute rheumatic fever (Stott, 1938; Banerjea, 1935; Vakil, 1949). Padmavati (1962) presents data from different medical centres in India to show that the incidence of some of the major criteria such as chorea $(2 \%)$, nodules $(1 \%)$, and erythema marginatum $(0 \cdot 1 \%)$ are very low compared to Western figures (Bland and Jones, 1951; Massell, Fyler, and Roy, 1958).

A recent study in Mexico City suggested that rheumatic fever was more prevalent in temperate than in tropical zones (Mallén, Evans, and Balcázar, 1957). This was not due to the rarity of upper respiratory infections in tropical zones where the rate of streptococcal carriers was as high and the anti-streptolysin titre was higher than in the temperate zones: the authors concluded that the tropical climate affected the response of the host to "rheumatogenic influences".

Rheumatic heart disease formerly was one of the commonest forms of cardiac ailment in England, North Western Europe, and the U.S.A. This, however, has changed in the past 25 . years, and now rheumatic heart disease occupies third place to coronary arterial and hypertensive heart disease (Padmavati, 1958). In underdeveloped countries, the incidence of rheumatic heart disease is still high: India 39 per cent (Padmavati, 1962); Mexico 41 per cent (Chavez, 1942); and Philippines 47 per cent (Alimurung et al., 1955). The role of overcrowding and malnutrition is difficult to assess: in this country a nutritional survey of a rural population has shown that the percentage of families with an intake of less than 50 per cent of the recommended allowance of riboflavine, vitamin A, ascorbic acid, fats, calcium, and iron, was very high. The intake of protein in 60 per cent of these families was low (Rao and Rao, 1958).

It has been argued that mitral valvotomy should not be undertaken in childhood or adolescence because of the risk of operating during a phase of active rheumatic carditis and because recurring. rheumatic activity may be provoked (Baker, Brock, and Campbell, 1950; Sellors et al., 1953).

It is commonly believed that the valvular defects in young patients are relatively insignificant and that persisting carditis is mainly responsible for deterioration. The importance of active carditis should not be minimized. At the same time the extreme narrowing of the mitral valve as found at operation in our young patients, the very high left atrial end diastolic pressure, and the striking improvement after valvotomy emphasize the importance of the valvular component. In a few instances we have noticed that subacute carditis could be controlled only after mitral valvotomy. Borman et al. (1961) report on 2 patients with a recurrence of rheumatic activity over a period of five years: both of them were operated on during a phase of low grade rheumatic activity under cover of adrenocorticosteroids. There was no rheumatic flare-up during the follow-up period of four years and one year respectively. This may be the result of improved myocardial nutrition after mitral valvotomy (Gray, 1958). Of our 126 patients, 2 had a rheumatic flare-up in the first week after operation: both made a good recovery, and during the follow-up period had kept well and free of rheumatic reactivation. A somewhat high incidence of rheumatic activation was present in both our young $(15 \%)$ and old $(17 \%)$ patients during the follow-up period. We know that very few of them are able to continue on penicillin or sulphonamides for long-term prophylaxis, which may be important in this country. In Israel, Borman et al. (1961) were able to follow up 12 young patients for five years with no episodes of rheumatic reactivation: all these were on long-term penicillin prophylaxis.

It has been stated that there is a risk of restenosis after successful valvotomy, especially if active rheumatism should recur and this is obviously greater the younger the patient (Gray, 1958). It is unlikely that continuing or recurring rheumatic activity is commonly responsible for restenosis (Wilcken, 1960; Logan, Lowther, and Turner, 1962). During our follow-up, only one patient developed restenosis. Borman et al. (1961) have followed 12 young patients for five years, and restenosis did not occur in any of them. It is possible that our incidence of restenosis may vary with future observations. The results, so far, have been encouraging. 


\section{Summary AND Conclusions}

Mitral valvotomy was performed on 126 patients below 20 years (average 15.5 years). The unusual features were the slight male preponderance, short duration of symptoms, the degree of incapacity, and the low incidence of embolism, atrial fibrillation, and calcification of the mitral valve. Pulmonary hypertension was present in all the patients and in a few who had right heart catheterization, the pulmonary arterial systolic pressure averaged $81 \mathrm{~mm}$. $\mathrm{Hg}$ : in one patient it was $150 \mathrm{~mm}$. Hg.

The mitral valve was extremely narrowed in the majority of patients. The direct left atrial pressure recorded in 23 patients showed an average left atrial end diastolic pressure of $23 \mathrm{~mm} . \mathrm{Hg}$, again reflecting the severe stenosis.

The mortality was slightly higher than the usual reports. There was no evidence to attribute this to persisting rheumatic carditis. It was more likely to be related to the severe pulmonary hypertension and poor general condition, as there was a striking increase in mortality in grade 3 and grade 4 patients.

The late follow-up showed excellent and good results in 68 per cent and a fair result in 28 per cent. There was an appreciable incidence of rheumatic reactivation in both young and old patients, the great majority of whom were not on long-term chemo-prophylaxis. There was no correlation between the histological evidence of rheumatic activity (atrial biopsy) and rheumatic recurrences.

Restenosis was observed in only one patient, four years after operation.

It is concluded that the pattern of rheumatic heart disease in India differs from that in the Western hemisphere in that critical mitral stenosis develops early in a large number of young patients, in whom there are clear indications for early operation.

We are greatly indebted to Mr. P. S. S. Rao and Mr. G. Jesudian for help with the analysis of the edge-marking cards. Many house physicians and registrars have helped us at various stages, but particular mention must be made of Dr. T. V. Joseph and Dr. S. S. Narasimhan. We also want to thank Mr. R. Mohanavelu for secretarial help.

\section{REFERENCES}

Alimurung, M. M., Herrera, F., Guytingco, A., and Cruz, P. M. (1955). Heart disease in the Philippines: A sevenyear (1947-1953) postwar survey of four Manila general hospitals. Amer. Heart J., 50, 293.

Angelino, P. F., Levi, V., Brusca, A., and Actis-Dato, A. (1956). Mitral commissurotomy in younger age group. Amer. Heart J., 51, 916.

Bailey C. P., and Bolton H. E. (1956). Criteria for and results of surgery for mitral stenosis. N. Y. med. J., 56, 825.

Baker, C., Brock, R. C., and Campbell, M. (1950). Valvulotomy for mitral stenosis; report of six successful cases. Brit. med. J., 1, 1283.

, and Hancock, W. E. (1960). Deterioration after mitral valvotomy. Brit. Heart J., 22, 281.

Banerjea, J. C. (1935). Rheumatic heart disease in childhood. Indian J. Pediat., 2, 279.

Bland, E. F., and Jones, T. Duckett (1951). Rheumatic fever and rheumatic heart disease: a twenty-year report on 1000 patients followed since childhood. Circulation, 4, 836.

Borman, J. B., Stern, S., Shapira, T., Milwidsky, H., and Braun, K. (1961). Mitral valvotomy in children. Amer. Heart J., 61, 763.

Chavez, I. (1942). The incidence of heart disease in Mexico. A study of 2,400 cases of organic heart disease. Amer. Heart J., 24, 88.

Davies, L. G., Goodwin, J. F., Steiner, R. E., and Van Leuven, B. D. (1953). The clinical and radiological assessment of the pulmonary arterial pressure in mitral stenosis. Brit. Heart J., $15,393$.

Ellis, L. B., Harken, D. E., and Black, H. (1959). A clinical study of 1,000 consecutive cases of mitral stenosis two to nine years after mitral valvuloplasty. Circulation, 19, 803.

Glover, R. P. (1959). Mitral surgery in a young girl. Amer. J. Cardiol., 4, 132.

Goodwin, J. F., Hunter, J. D., Cleland, W. P., Davies, L. G., and Steiner, R. E. (1955). Mitral valve disease and mitral valvotomy. Brit. med. J., 2, 573 .

Gray, I. R. (1958). Mitral valvotomy in the young. Lancet, 2, 1263. Keith, J. D., Rowe, R. D., and Vlad, P. (1958). Heart Disease in Infancy and Childhood, p. 612. Macmillan, New

Kerley, P. (1933). Radiology in heart disease. Brit. med. J., 2, 594.

Logan, A., Lowther, C. P., and Turner, R. W. D. (1962). Reoperation for mitral stenosis. Lancet, $1,443$. , and Turner, R. (1953). Mitral stenosis: diagnosis and treatment. Lancet, 1, 1007 and 1057.

(1959). Surgical treatment of mitral stenosis; with particular reference to the transventricular approach with a mechanical dilator. Lancet, $2,874$. 
Mallén, M. S., Evans, M., and Balcázar, J. (1957). Further studies on rheumatic fever epidemiology: comparative incidence of rheumatic fever, streptococcal carriers, and antistreptolysin titers in the tropics and in Mexico City. Amer. Heart J., 53, 767.

Massell, B. F., Fyler, D. G., and Roy, S. B. (1958). The clinical picture of rheumatic fever. Amer. J. Cardiol., 1, 436. Padmavati, S. (1958). A five year survey of heart disease in Delhi (1951-1955). Indian Heart J., $10,33$. (1962). Epidemiology of cardiovascular disease in India. I. Rheumatic heart disease. Circulation, $25,703$. Papp, C., and Zion, M. M. (1956). The postcommissurotomy syndrome. Brit. Heart J., 18, 153.

Rao, B. R. H., and Rao, P. S. S. (1958). General health and nutrition survey of the rural population in Pannathur. Part III. The quantitative dietary survey. Indian J. med. Sci., 12, 726.

Sellors, T. H., Bedford, D. E., and Somerville, W. (1953). Valvotomy in treatment of mitral stenosis. Brit. med.J., 2, 1059.

Stott, H. (1938). The incidence of rheumatic infection in India. Indian med. Gaz., 73, 271.

Vaishnava, S., Webb, J. K. G., and Joseph, C. (1960). Juvenile rheumatism in South India. Indian J. Child Hlth., 9, 290.

Vakil, R. J. (1949). A study of rheumatic heart disease in Bombay Province, India. Indian Heart J., $1,15$.

Wilcken, D. E. L. (1960). Mitral valvotomy and restenosis. Brit. med. J., 1, 681.

Wood, P. (1954a). An appreciation of mitral stenosis. Part I. Clinical features. Brit. med. J., $1,1051$. (1954b). An appreciation of mitral stenosis. Part II. Investigations and results. Brit. med. J., 1, 1113. 